\title{
Influence of Cutting Speed and Feed Rate on the Wear of an S-Type Mixed Ceramic Tool in Turning of AISI 4140 Hardened Steel
}

\author{
Jeferson H. W. NICOLODI, Luiz A. CONSALTER, Orlando DURÁN, André J. SOUZA
}

\begin{abstract}
In this study, the performance and the useful life of a mixed ceramic tool with S-type edge microgeometry are evaluated for the case of dry turning of AISI 4140 steel hardened to $55 \mathrm{HRC}$. The influence of the cutting speed and feed rate of the cutting parameters on the tool failure was investigated. The experiments were designed and analysed using the complete factorial design technique. Our results indicate that the cutting speed and feed rate values exert significant influence on the tool lifespan. Crater and flank wear occur in all cutting conditions. The predominant tool wear mechanisms are diffusion, abrasion, and adhesion, which are also known as attrition. The tool life curve and equation were established for the machining conditions of this investigation to achieve the subsequent optimisation of this process.
\end{abstract}

Keywords: ceramic tool; cutting parameters; tool wear and life; hardened steel turning

\section{INTRODUCTION}

Until recently, grinding was a common finishing process for hardened workpieces $[1,2]$. However, in the last years, turning using modern cutting tools became an important alternative for machining of hardened steels (45 HRC) in modern industrial production and substituting more complex finishing processes. These steels are employed in an extensive range of industrial products, such as axes, bearings, cams, forged parts, dies and moulds [3]. Currently, turning using ceramic tools is considered to be an efficient alternative with a reasonable cost-benefit ratio, which can significantly boost productivity while simultaneously generating environmental benefits $[4,5]$. Besides, advances in technology produce rigid lathes with better dimensional precision and capabilities for higher speeds. At the same time, new tool materials with characteristics such as excellent and better structures and good resistance to wear at high temperatures emerge. These developments led to the use of turning for the machining of hardened steels, especially in finishing operations. Turning offers significant advantages compared to milling in terms of significant reduction of set up, production times and fabrication costs [6]. The most used tool materials for hard turning are mixed ceramics $(\mathrm{Al} 2 \mathrm{O} 3+\mathrm{TiC})$ and cubic boron nitride (CBN) [7]. According to Klocke [6], ceramics are the one of the most used materials in hardened steels machining because of certain characteristics that improve the performance and represent benefits when contrasted with milling. In turning of hardened steels, which are characterised by their low machinability, a series of difficulties can arise during the operation, such as: a significant amount of heat generated by friction, an important trend to vibrations, and high variability in the machining forces. These situations lead to increase of the wear rates and failures of cutting tools.

One of the most important aspects of increasing wear resistance is tool edge preparation [8]. In machining of hardened steels, the most common cutting tool edge profiles are the chamfered edge (T-type), the rounded edge (E-type), and the chamfered and rounded edge S-type [9]. Little information on the performance of S-type mixed ceramic tools in finishing of hardened steels is still available. Despite the importance of the tool geometry for turning and its effect on the chip formation, machining forces, tool wearing, surface finish and surface integrity [4, $9,10]$, the influence of the cutting parameters on the tool failures has not been investigated.

Considering the previously mentioned aspects, this study presents the results of the turning performance of an S-type mixed ceramic oxide tool coated with titanium nitride (TiN) for finishing AISI 4140 steels hardened to 55 HRC. The focus of this study is the influence of the cutting speed and feed rate on wearing process aiming at the creation of a tool life model. Supported by Kolahdoozan [11] who affirms that the wear model based on Taylor's equation constitutes a useful tool through which cutting speed-tool life optimisation can be carried out, this paper also aims at contributing to the correct planning and optimisation of this process.

\section{LITERATURE REVIEW}

Despite its importance, few studies have investigated the performance of ceramic tools with special microgeometry, such as the S-type, in hard steel turning.

Davoudinejad and Noordin [12] explored the effect of T-type and E-type tool microgeometries in hardened steel turning using a mixed ceramic tool $\left(\mathrm{Al}_{2} \mathrm{O}_{3}+\mathrm{TiC}\right)$. The authors observed longer tool lives when using chamfered edge tools in several cutting conditions with predominant flank and crater wear and abrasive effects. According to these researchers, crater wear emerges due to the significant percentage of carbon in titanium carbide in the tool matrix, which enables greater chemical affinity between tool and workpiece's material, resulting in a diffusive wear mechanism.

Godoy and Diniz [13] evaluated the behaviour of mixed ceramic tools and $\mathrm{CBN}$ in the dry turning of hardened AISI 4340 steel and concluded that the predominant types of wear were flank and crater wear. Abrasion was the main wear mechanism that occurred in the ceramic tools. According to the authors, the friction between tool and workpiece causes abrasion due to hard elements (carbides, nitrides and oxides) of the machined material and the hard fragments removed from the tool (attrition). 
Das et al. [14] turned hardened AISI 4140 steel using mixed ceramic tools. The results indicated that flank wear is directly influenced by cutting speed. These authors also explained that high cutting speed values increase the temperature in the cutting region due to the rapid friction between tool and workpiece beyond the tool material's thermal stability limits, which causes flank wear. The authors also commented that the friction between tool surface and chips at high cutting speeds (with high heat) and high pressures (that originate from the feed rate or its increase) caused crater wear. Crater wear causes the removal of particles from the tool's rake surface. Other authors highlight similar results [15-19].

Singh \& Rao [20] investigated the development of a model to predict ceramic tool wear in turning of hardened steels. The authors performed a comprehensive literature review and identified the most relevant types of wear: flank wear, crater wear and notch wear.

Kaçal [21] performed a study of dry steel turning obtained by powder metallurgy - PMD23 (60 HRC) with using mixed ceramics coated with titanium nitride (TiN) cutting tool to investigate the effect of the variation in the cutting parameters on the surface roughness and tool wear. The results demonstrate that feed rate is the most influential parameter. An increase in feed rate was accompanied by a significant increase in workpiece's surface roughness values. This finding was verified by the most expressive feed rate marks on the machined surface. The results of this study are consistent with the results of other investigations [22-24].

\section{MATERIALS AND METHODS}

Fig. 1 shows the experimental setup for turning of AISI 4140 hardened steel.

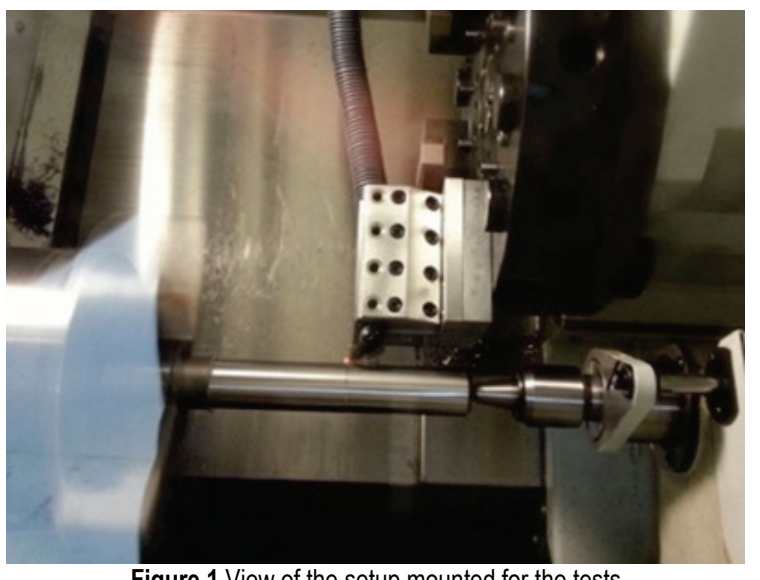

Figure 1 View of the setup mounted for the tests

The material in the tests consisted of AISI 4140 steel bars with $35 \mathrm{~mm}$ diameter and length of $200 \mathrm{~mm}$. The bars were chamfered with $45^{\circ} \times 5 \mathrm{~mm}$ on the cutting tool entry face. The material was tempered at $(55 \pm 1)$ HRC. Tab. 1 shows the chemical composition of this material.

Table 1 Chemical composition of AISI 4140 steel (\%wt).

\begin{tabular}{|c|c|c|c|c|c|c|c|c|}
\hline $\mathrm{C}$ & $\mathrm{Si}$ & $\mathrm{Mn}$ & $\mathrm{P}$ & $\mathrm{S}$ & $\mathrm{Cr}$ & $\mathrm{Mo}$ & $\mathrm{Ni}$ & $\mathrm{Cu}$ \\
\hline 0.41 & 0.21 & 0.87 & 0.02 & 0.02 & 1.01 & 0.15 & 0.07 & 0.13 \\
\hline
\end{tabular}

The Sandvik tools S-type correspond to mixed ceramic inserts $\left(70 \% \mathrm{Al}_{2} \mathrm{O}_{3}+30 \% \mathrm{TiC}\right) \mathrm{CNGA} 120408 \mathrm{~S} 01525$
6050, which are coated with titanium nitride (TiN) and have S-type chamfered and rounded edge microgeometry. DCLNL 2020K12 $\left(\alpha=6^{\circ}, \kappa_{\mathrm{r}}=-5^{\circ}, \gamma=-6^{\circ}, \lambda=-6^{\circ}\right)$ Sandvik tool holder was employed. To evaluate the hardness uniformity of the sample test bodies, a microhardness meter Shimadzu model HMV-G20 was used. The applied load was $20 \mathrm{~N}$ with $15 \mathrm{~s}$ per impression. The distance defined between each impression was $1 \mathrm{~mm}$ measured from the periphery to the centre of the circle.

The machining tests were performed in a turning centre Romi model GL $240 \mathrm{M}$, with $14.7 \mathrm{~kW}$ of power, a maximum spindle speed of $6000 \mathrm{rpm}$, a three-jaw chuck, and a countershaft of $110 \mathrm{Nm}$ maximum torque.

The stereo binocular microscope Zeissmodel Stemi 2000-C with maximum magnification of $50 \times$ was used to record wear data and measure the optical images. The microscopy observations were performed with the aid of a Tescan scanning electron microscopy (SEM), model Vega LM3, with zoom capabilities on the order of $300000 \times$. The semi-quantitative chemical composition analyses in the tool's worn regions were performed using the same equipment. Energy-dispersive X-ray spectrometry (EDS) using an Oxford Instruments spectrometer was employed for the chemical composition analysis of the steel.

The cutting parameters (cutting speed $v_{\mathrm{c}}$, feed rate $f$ and depth of cut $a_{\mathrm{p}}$ ) were determined according to intervals of values that are commonly employed in the industry such that they remained within the limits recommended by the tool manufacturer for finishing operations. The cutting parameters chosen for the turning tests and their corresponding levels are listed in Tab. 2. Therefore, three $v_{\mathrm{c}}$ values and two values of $f$ were adopted. Based on the results of dynamic stability tests performed by Jang \& Hsiao [25] under similar conditions to those used in this work and, in order to avoid the influence of vibrations during the experiments, $a_{\mathrm{p}}=0.3 \mathrm{~mm}$ was adopted.

In the case of finishing operations, with a low depth of cut, where a small edge area makes contact with the workpiece, the flank wear $V B_{\mathrm{C}}=100 \mu \mathrm{m}$ was adopted as an end of life criterion. Moreover, that value was adopted considering the results of initial tests. In those tests, where extreme cutting conditions were used until $t_{\mathrm{c}}=50 \mathrm{~min}$, $V B_{\mathrm{C}}$ values between 100 and $150 \mu \mathrm{m}$ were observed.

Table 2 Cutting parameters

\begin{tabular}{|l|c|c|c|}
\hline Cutting speed, $v_{\mathrm{c}}(\mathrm{m} / \mathrm{min})$ & 120 & 135 & 150 \\
\hline Feed rate, $f(\mathrm{~mm} / \mathrm{rev})$ & 0.11 & 0.22 \\
\hline Depth of cut, $a_{\mathrm{p}}(\mathrm{mm})$ & \multicolumn{3}{|c|}{0.30} \\
\hline
\end{tabular}

The time intervals adopted for the wear measurements and the tool failure analysis were based on the normalised Renard series (R10), which produced the following sequence: 1, 2, 4, 6.3, 10, 12.5, 16, 20, 25, 31.5, 40 and $50 \mathrm{~min}$. Thus, the tests were interrupted when a cutting time of $50 \mathrm{~min}$ (end of life criteria) was attained.

After each one of that time intervals, the tool wear was measured, and the tool failure images were analysed using the pre-established cutting times to elaborate graphs and data interpretation. The statistical software Minitab developed the factorial planning and the LAB Fit Curve Fitting Software generated the surface graph. 


\section{RESULTS AND DISCUSSION}

\subsection{Effect of the Cutting Speed and the Feed Rate on the Tool Faults}

The flank wear $\left(V B_{\mathrm{C}}\right)$ and notch wear $\left(V B_{\mathrm{N}}\right)$ images, as a function of the variation of the cutting speed $\left(v_{\mathrm{c}}\right)$ and the feed rate $(f)$ at a machining time of 50 min are displayed in Fig. 2.

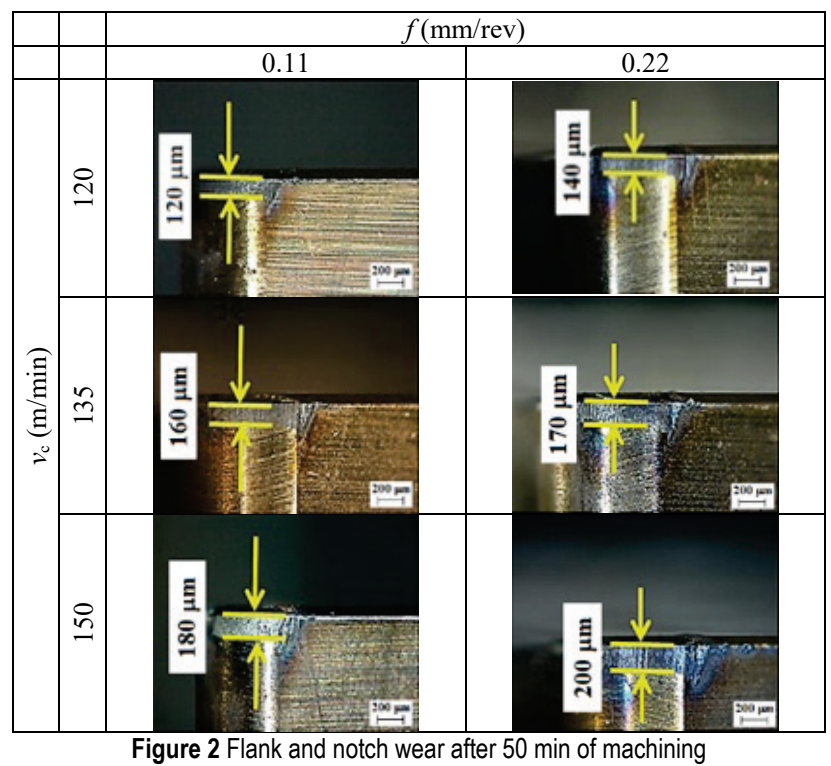

As expected, the highest $V B_{\mathrm{C}}$ values were noted at the fastest cutting speed $(150 \mathrm{~m} / \mathrm{min})$ and the lowest values were verified at the lowest cutting speed $(120 \mathrm{~m} / \mathrm{min})$. The increase of $V B_{\mathrm{C}}$ with the feed rate $(f)$ was also noted, although to a lower extent. This wear was directly influenced by the cutting speed due to the intense friction between tool and machined surface, whereas the predominant wear mechanism for the tool tip was mechanical abrasion due to the tool friction against a hardened piece. These results are similar to the findings obtained by other researchers [14-16, 18, 19].

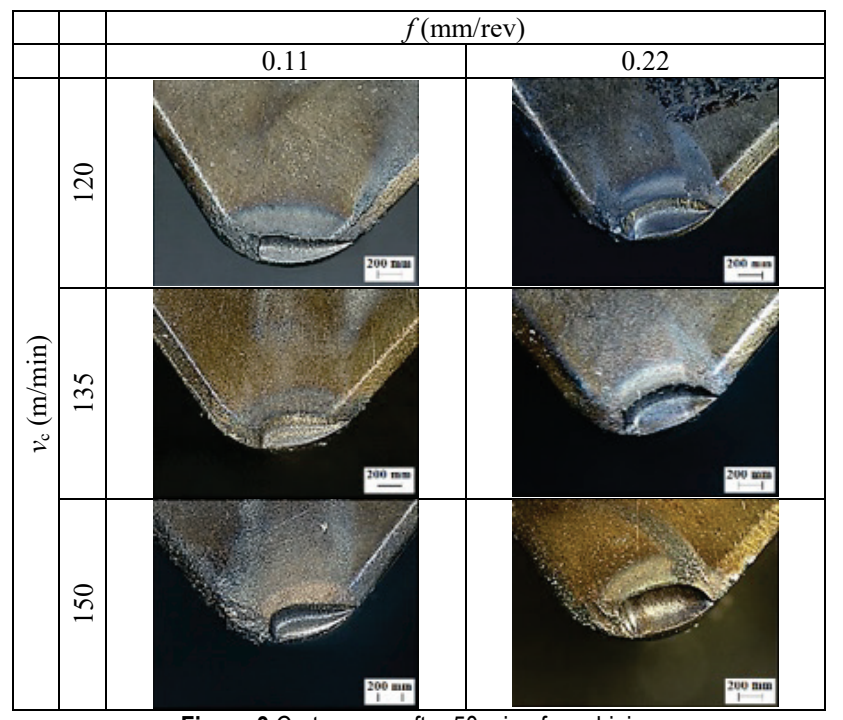

Figure 3 Crater wear after 50 min of machining

Similarly, the effect of the increase in feed rate produced higher $V B_{C}$ values. Notch wear probably occurs due to the increase of oxides that continuously form and adhere to the tool in the regions near the chip-tool interface. The influence of the breakage of the adherence bonds between the oxides and the tool, which is promoted by the attrition mechanism, causes the removal of the surface material from the tool [26]. Another probable cause of notch wear is the tool fatigue that is caused by the variation in the free surface strength, accompanied by small lateral movements of the chip edges [27].

The images in Fig. 3 illustrate the crater wear under the influence of the cutting speed $\left(v_{\mathrm{c}}\right)$ and feed rate $(f)$ variation for a cutting time of $50 \mathrm{~min}$.

The friction between tool and chips produced the crater wear identified during the tests over the tool's rake surface. Due to the high cutting speeds, the diffusion wear mechanism is activated once the presence of $30 \% \mathrm{TiC}$ in the tool matrix elevates the chemical affinity of the $\mathrm{C}$ present in the chemical compound $\mathrm{TiC}$ with the chemical elements in the workpiece material, which causes the removal of particles from the tool's rake surface. These results are consistent with the results obtained by investigations performed by [14-17, 27].

\subsection{Investigations on Tool Wear Mechanisms}

To investigate the failure and wear mechanisms, we analysed the tool wear by SEM/EDS to identify the presence or absence of material micro- or nano layers on the tool face or flank and the corresponding chemical elements that may explain these failures. The analyses were performed on tools that were near the end of their useful life (50 min of machining), considering all cutting conditions in the tests.

Fig. 4 illustrates the S-type ceramic insert prior to the tests ( 0 min of machining) and highlights the main points analysed by SEM. As shown in Fig. 5, the tool chemical composition spectroscopy (EDS) under these conditions demonstrated the presence of the following chemical elements: O, Al, Ti, C, N and $\mathrm{Zr}$.

The SEM/EDS analyses performed on the tool before the tests were repeated on all inserts under the end of life condition (50 min of machining time). However, only the conditions $v_{\mathrm{c}}=120 \mathrm{~m} / \mathrm{min}$ and $f=0.11 \mathrm{~mm} / \mathrm{rev}$ will be discussed in this section, as the wear mechanisms that were detected after the analyses were similar for all cutting conditions. Fig. 6 highlights typical failure that occurred under all cutting conditions after a machining time of 50 $\min$.

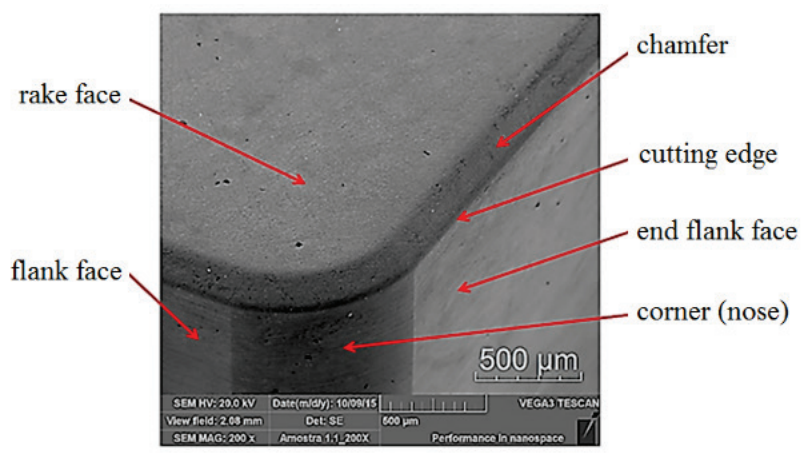

Figure 4 Detailed view of the plate before the tests (new) 


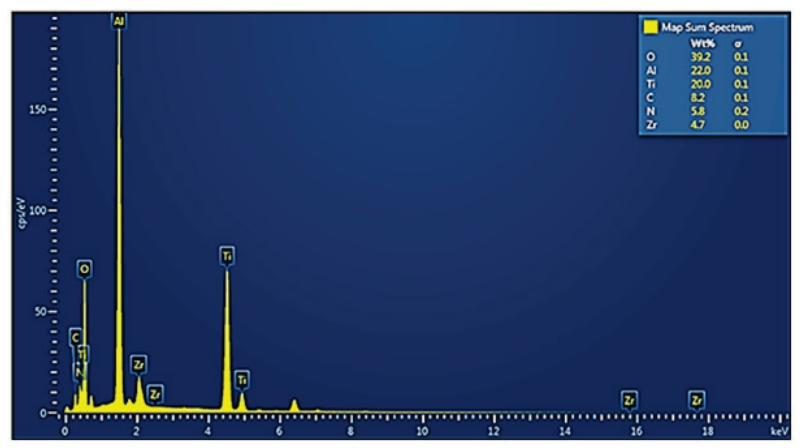

Figure 5 SEM/EDS chemical composition spectrum of the tool before the tests (new)

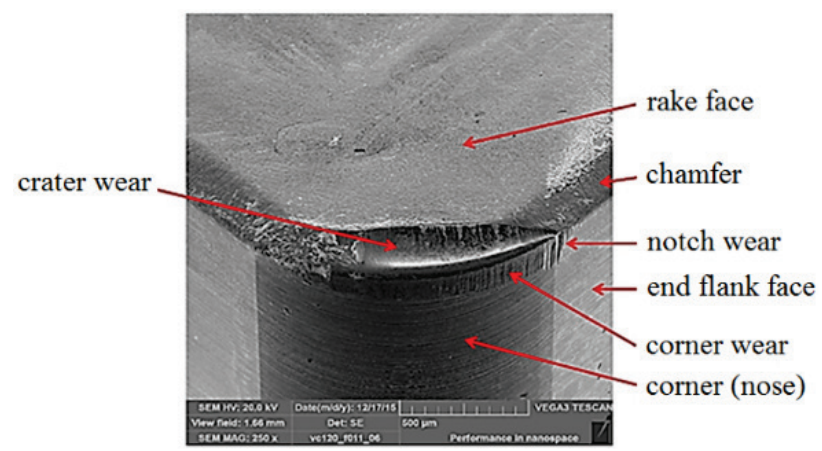

Figure 6 Detailed view of the ceramic tool pointing at the common failures that occurred at the end of the tests after 50 min of machining

The tool tip observed with SEM/EDS under $v_{\mathrm{c}}=120$ $\mathrm{m} / \mathrm{min}$ and $f=0.11 \mathrm{~mm} / \mathrm{rev}$ is shown in Fig. 7a. Thus, the regions where the crater $[\mathrm{A}]$, edge $[\mathrm{B}]$ and corner wear $[\mathrm{C}]$ wear were analysed are represented in the image of Fig. $7 \mathrm{~b}$.

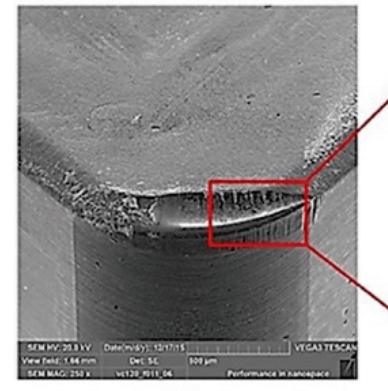

(a)

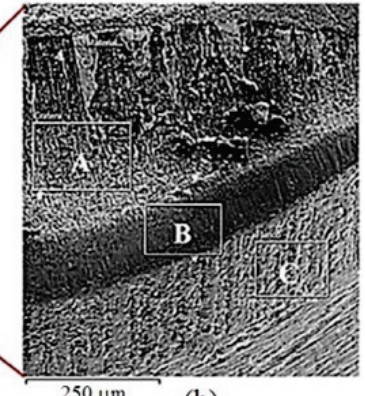

(b)
Figure 7 (a) Tool tip under the cutting conditions $v_{\mathrm{c}}=120 \mathrm{~m} / \mathrm{min}$ and $f=0.11$ $\mathrm{mm} / \mathrm{rev}$; (b) tool wear regions: $[\mathrm{A}]$ face, $[\mathrm{B}]$ cutting edge and $[\mathrm{C}]$ flank

The results from the spectroscopies performed in the regions $[\mathrm{A}],[\mathrm{B}]$ and $[\mathrm{C}]$ can be visualised in Fig. 8, Fig. 9 and Fig. 10, respectively.

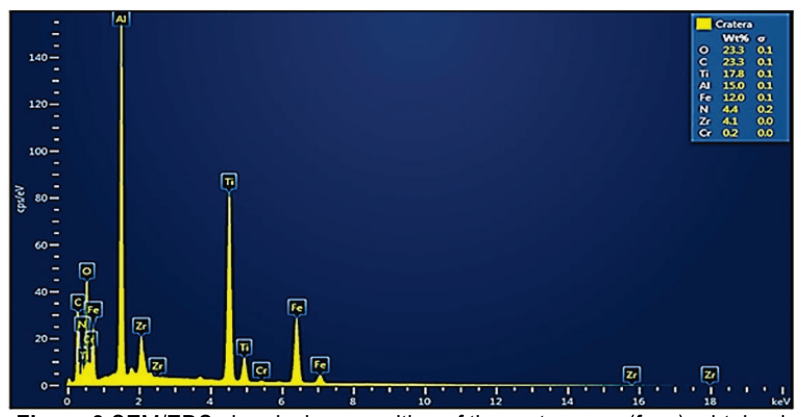

Figure 8 SEM/EDS chemical composition of the crater wear (face), obtained from region $[A]$ of Fig. $8 \mathrm{~b}$

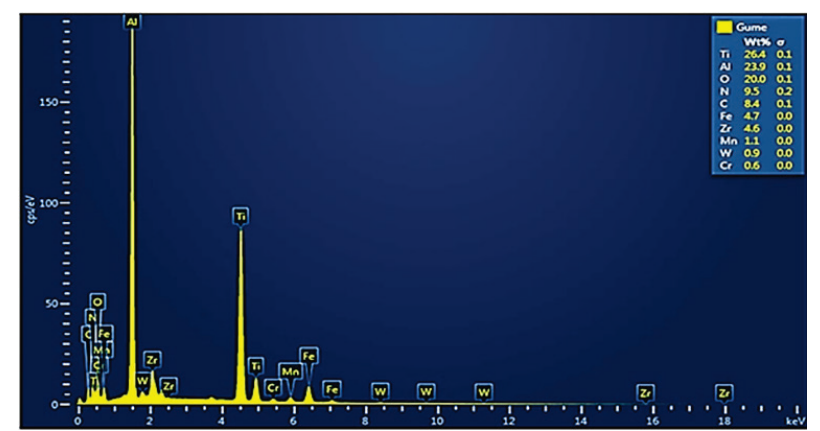

Figure 9 SEM/EDS chemical composition of the tool edge, obtained from region $[B]$ of Fig. 8b

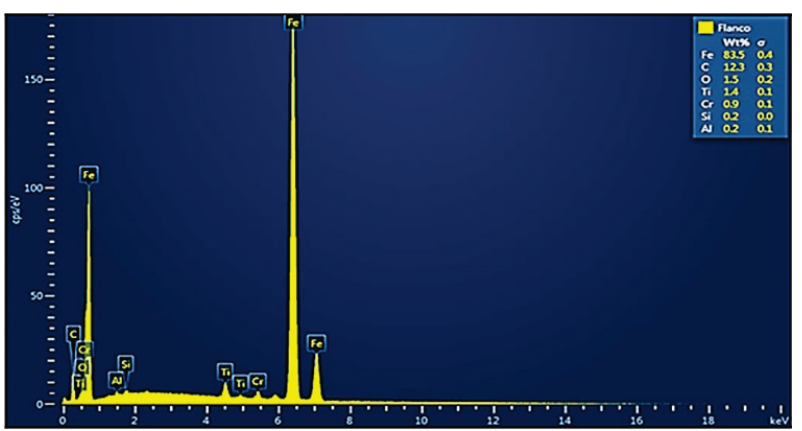

Figure $10 \mathrm{SEM} / \mathrm{EDS}$ chemical composition of the flank wear, obtained from region $[\mathrm{C}]$ of Fig. $8 \mathrm{~b}$

The analyses performed through SEM indicated that the dominant failure modes were crater wear, corner wear and notch wear. No damage occurred in the tools during the tests. Regarding wear mechanisms, the attrition mechanism was present in all observations of the tool corner, edge and face.

Due to the friction between the workpiece and the tool tip produced by the hardened elements (carbides, nitrides and oxides) in the machined material and the removal of hard fragments from the tool, the presence of vertical marks parallel to the cut direction is the evidence of the tip wear by mechanical abrasion.

The results obtained from EDS analysis indicated the presence of chemical elements from the machined material ( $\mathrm{Fe}, \mathrm{Cr}, \mathrm{Mn}, \mathrm{W}$ and $\mathrm{Si}$ ) on the flank, on the edge and inside the crater, which is attributed to the joint actions of the diffusion, abrasion and attrition wear mechanisms.

The crater identified in the tools primarily appears due to the diffusion wear mechanism once the presence of carbon $(\mathrm{C})$ from the titanium carbide $(\mathrm{TiC})$ of the ceramic plate matrix produces chemical affinity between the elements in the machined piece. Similar results have been cited in other studies [12, 14, 19, 27-32].

\subsection{Tool Life Curve}

The tool life curve is dependent on a series of factors during the machining process. It is highly dependent on the cutting speed and is dependent to a lesser extent on the feed rate. Fig. 11 and Fig. 12 illustrate the tip wear for different cutting speeds, considering the feed rates of $f=0.11$ $\mathrm{mm} / \mathrm{rev}$ and $f=0.22 \mathrm{~mm} / \mathrm{rev}$.

Tab. 3 presents the tool life $(T)$ for different cutting conditions according to $V B_{\mathrm{C}}=0.1 \mathrm{~mm}$.

Eq. (1) and Eq. (2), with $R^{2}=0.994$ and $R^{2}=0.946$, respectively, rule the tool life curves denoted by Fig. 13 
using log-log scale plot for the corresponding values of feed rate $(0.11$ and $0.22 \mathrm{~mm} / \mathrm{rev}$ respectively).

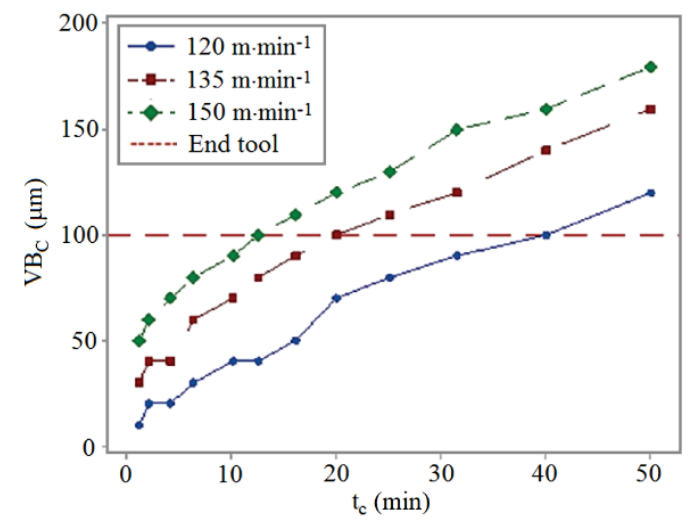

Figure 11 Flank wear $\left(V B_{\mathrm{C}}\right)$ as a function of cutting time for the condition $f=0.11 \mathrm{~mm} / \mathrm{rev}$

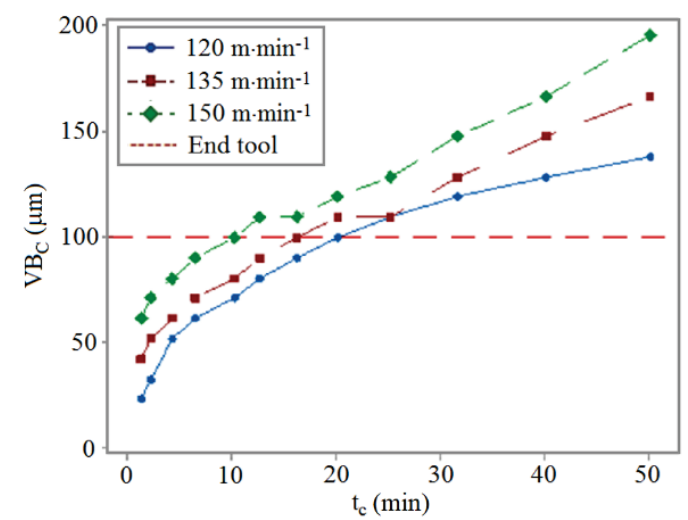

Figure 12 Flank wear $\left(V B_{C}\right)$ as a function of cutting time for the condition $f=0.22 \mathrm{~mm} / \mathrm{rev}$

\begin{tabular}{|c|c|c|} 
Table 3 Ceramic tool lifespan $\left(a_{\mathrm{p}}=0.3 \mathrm{~mm}\right)$ \\
\hline \multirow{2}{*}{$v_{\mathrm{c}}(\mathrm{m} / \mathrm{min})$} & $f(\mathrm{~mm} / \mathrm{rev})$ & $T(\mathrm{~min})$ \\
\hline \multirow{2}{*}{120} & 0.11 & 40 \\
\cline { 2 - 3 } & 0.22 & 20 \\
\hline \multirow{2}{*}{135} & 0.11 & 20 \\
\cline { 2 - 3 } & 0.22 & 16 \\
\hline \multirow{2}{*}{150} & 0.11 & 12.5 \\
\cline { 2 - 3 } & 0.22 & 10 \\
\hline
\end{tabular}

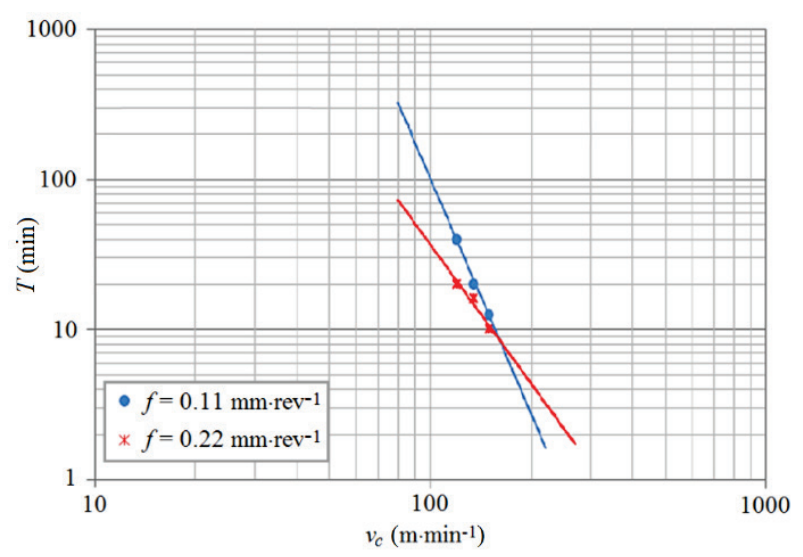

Figure 13 Tool life curve

$$
\begin{aligned}
& T=\left(2.8607 \times 10^{12}\right) \cdot v_{\mathrm{c}}^{-5.226} \\
& T=\left(5.3671 \times 10^{7}\right) \cdot v_{\mathrm{c}}^{-3.083}
\end{aligned}
$$

As shown in Fig. 13, for the lowest feed rate condition $(f=0.11 \mathrm{~mm} / \mathrm{rev})$, the tool life $(T)$ is more sensitive to the increase in cutting speed $\left(v_{\mathrm{c}}\right)$, and the curves intersect at $T=8.5 \mathrm{~min}$ and at a cutting speed of $v_{\mathrm{c}}=160 \mathrm{~m} / \mathrm{min}$.

The tool CNGA 120408 S 015256050 life equations can be employed to optimise the process. However, their application is conditioned by the rigorous observation of the parameter intervals in this experiment. The combined effects of the cutting speed $\left(v_{\mathrm{c}}\right)$ and feed rate $(f)$ on the tool life $(T)$ are represented in Fig. 14.

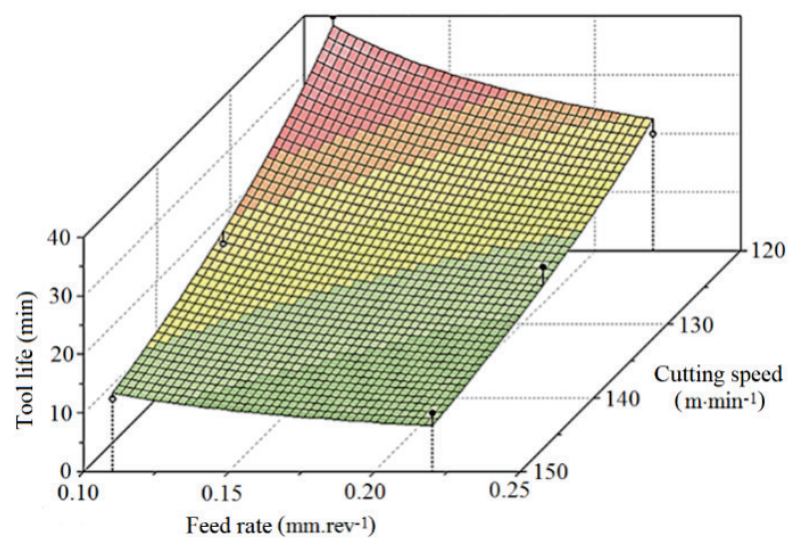

Figure 14 Surface of the combined effects of the cutting speed $\left(v_{\mathrm{c}}\right)$ and the feed rate $(f)$ over the lifespan $(T)$

Eq. (3) represents the surface plot graph $3 \mathrm{D}$ assisted by LAB Fit presented by Fig. $14\left(R^{2}=0.953\right)$.

$$
T=\left(4.1435 \times 10^{10}\right) \cdot f^{-0.773} \cdot v_{\mathrm{c}}^{-4.70}
$$

A significant superiority of the cutting speed $\left(v_{\mathrm{c}}\right)$ is observed over the tool life $(T)$ (exponents of Eq. 3). The effect of $v_{\mathrm{c}}$ on $T$ is larger at smaller feed rates $(f)$, and the effect of $f$ on $T$ is more pronounced at lower values of $v_{\mathrm{c}}$.

\section{CONCLUSIONS}

The performance of an S-type mixed ceramic tool for the turning of AISI 4140 steel hardened to $(55 \pm 1)$ HRC was investigated. Regarding the tool failures, wear mechanisms and the tool life $(T)$ we analysed the effect of the cutting speed $\left(v_{\mathrm{c}}\right)$ and feed rate $(f)$. Based on the results of this work, the following conclusions can be marked:

- The $v_{\mathrm{c}}$ and $f$ exert a significant influence on $T$, as their increase causes a reduction in $T$.

- Tool flank wear $\left(V B_{\mathrm{C}}\right)$ was directly influenced by $v_{\mathrm{c}}$ due to the rapid friction between tool and machined surface. In the lowest $f$ condition, $T$ is more sensitive to an increase in $v_{\mathrm{c}}$.

- No damage occurred (cracking or fractures) during operations. The predominant types of tool failures were flank wear, crater wear and notch wear.

- Wear mechanisms were abrasion, attrition and diffusion. Abrasion is the main acting wear mechanism; the chemical affinity of carbon in the titanium carbide matrix of ceramic tool and elevated process temperatures stimulate the diffusion wear mechanism, which contributes to crater wear rate.

- Tool life curves and equations obtained in this study can be effectively used in optimization processes. However, their application is conditioned to a rigorous 
observation of the value intervals of the parameters used in this experiment.

- $\quad T$ based on the simple Taylor equation, appeared to be more sensitive to an increase $v_{\mathrm{c}}$ under the lowest $f$.

- $\quad$ Considering the combined effects of $v_{\mathrm{c}}$ and $f$, a greater effect in $T$ occurs with a combination of lower values of both $v_{\mathrm{c}}$ and $f$, with a major effect of $v_{\mathrm{c}}$ over $f$.

- With regard to the sensitivity of joint effects, the greater influence of $f$ at low $v_{\mathrm{c}}$ and the greater influence of crater wear for low $f$ were verified.

\section{ACKNOWLEDGEMENTS}

The authors thank ARWI (Sandvik Coromant Technical Distributor), for the donation of mixed ceramic S-type inserts, and STARA S/A (Agricultural Equipment Manufacturer Industry) for the donation of AISI 4140 steel.

\section{REFERENCES}

[1] Srithar, A., Palanikumar, K., \& Durgaprasad, B. (2014). Experimental Investigation and Surface roughness Analysis on Hard turning of AISI D2 Steel using Coated Carbide Insert. Procedia Engineering, 97, 72-77. https://doi.org/10.1016/j.proeng.2014.12.226

[2] Bartarya, G. \& Choudhury, S. K. (2012). State of the art in hard turning. International Journal of Machine Tools and Manufacture, 53(1), 1-14. https://doi.org/10.1016/j.jimachtools.2011.08.019

[3] Dumpala, R., Chandran, M., \& Rao, M. S. R. (2015). Engineered CVD Diamond Coatings for Machining and Tribological Applications. JOM, 67(7), 1565-1577. https://doi.org/10.1007/s11837-015-1428-2

[4] Chinchanikar, S. \& Choudhury, S. K. (2015). Machining of hardened steel - Experimental investigations, performance modeling and cooling techniques: A review. International Journal of Machine Tools and Manufacture, 89, 95-109. https://doi.org/10.1016/j.jimachtools.2014.11.002

[5] Ånmark, N., Björk, T., Ganea, A., Ölund, P., Hogmark, S., Karasev, A., \& Jönsson, P. (2015). The effect of inclusion composition on tool wear in hard part turning using PCBN cutting tools. Wear, 334-335, 13-22. https://doi.org/10.1016/j.wear.2015.04.008

[6] Klocke, F. (2011). Manufacturing processes 1 - Cutting. $R W T H$. Berlin: Springer. https://doi.org/10.1007/978-3-642-11979-8

[7] Dureja, J. S., Gupta, V. K., Sharma, V. S., \& Dogra, M. (2011). Investigating wear mechanisms of CBN and mixedceramic tools during finish hard turning of low-medium hardness AISI H11 steel. Int. J. Machining and Machinability of Materials, 10(1-2), 120-136. https://doi.org/10.1504/IJMMM.2011.040859

[8] Denguir, L. A., Besnard, A., Fromentin, G., Poulachon, G., \& Zhu, X. (2016). Flank wear prediction in milling AISI 4140 based on cutting forces PCA for different cutting-edge preparations. Int. J. Machining and Machinability of Materials, 18(3), 273-287. https://doi.org/10.1504/IJMMM.2016.076278

[9] Davim, J. P. (2011). Machining of Hard Materials. London: Springer. https://doi.org/10.1007/978-1-84996-450-0

[10] Dogra, M., Sharma, V. S., \& Dureja, J. (2011). Effect of tool geometry variation on finish turning-A Review. Journal of Engineering Science and Technology Review, 4(1), 1-13. https://doi.org/10.25103/jestr.041.01

[11] Kolahdoozan, M., Azimifar, F., \& Yazdi, S. R. (2014). Finite element investigation and optimization of tool wear in drilling process of difficult-to-cut nickel base superalloy using response surface methodology. International Journal of Advanced Design and Manufacturing Technology, 7(2), 67-76.

[12] Davoudinejad, A. \& Noordin, M. Y. (2014). Effect of cutting edge preparation on tool performance in hard-turning of DF3 tool steel with ceramic tools. Journal of Mechanical Science and Technology, 28(11), 4727-4736. https://doi.org/10.1007/s12206-014-1039-9

[13] Godoy, V. A. A. D. \& Diniz, A. E. (2011). Turning of interrupted and continuous hardened steel surfaces using ceramic and CBN cutting tools. Journal of Materials Processing Technology, 211(6), 1014-1025. https://doi.org/10.1016/j.jmatprotec.2011.01.002

[14] Das, S. R., Dhupal, D., \& Kumar, A. (2015). Study of surface roughness and flank wear in hard turning of AISI 4140 steel with coated ceramic inserts. Journal of Mechanical Science and Technology, 29(10), 4329-4340. https://doi.org/10.1007/s12206-015-0931-2

[15] El Hakim M. A., Abad, M. D., Abdelhameed, M. M., Shalaby, M. A., \& Veldhuis, S. C. (2011). Wear behaviour of some cutting tool materials in hard turning of HSS. Tribology International, 44(10), 1174-1181. https://doi.org/10.1016/j.triboint.2011.05.018

[16] Saini, S., Ahuja, I. S., \& Sharma, V. S. (2012). Influence of cutting parameters on tool wear and surface roughness in hard turning of AISI H11 tool steel using ceramic tools. International Journal of Precision Engineering and Manufacturing, 13(8), 1295-1302. https://doi.org/10.1007/s12541-012-0172-6

[17] Zhu, D., Zhang, X., \& Ding, H. (2013). Tool wear characteristics in machining of nickel-based superalloys. International Journal of Machine Tools and Manufacture, 64, 60-77. https://doi.org/10.1016/j.ijmachtools.2012.08.001

[18] Cheng, Y., Hu, H., Sun, S., \& Yin, Z. (2016). Experimental study on the cutting performance of microwave sintered $\mathrm{Al}_{2} \mathrm{O}_{3} / \mathrm{TiC}$ ceramic tool in the machining of hardened steel. International Journal of Refractory Metals and Hard Materials, 55, 39-46. https://doi.org/10.1016/j.jijmhm.2015.11.006

[19] Bensouilah, H., Aouici, H., Meddour, I., Yallese, M. A., Mabrouki, T., \& Girardin, F. (2016). Performance of coated and uncoated mixed ceramic tools in hard turning process. Measurement, 82, 1-18. https://doi.org/10.1016/j.measurement.2015.11.042

[20] Singh, D. \& Rao, P. V. (2010). Flank wear prediction of ceramic tools in hard turning. The International Journal of Advanced Manufacturing Technology, 50(5-8), 479-493. https://doi.org/10.1007/s00170-010-2550-5

[21] Kaçal, A. (2014). Investigation of Cutting Performance of the Ceramic Inserts in Terms of the Surface Roughness and Tool Wear at Turning of PMD 23 Steel. Applied Mechanics \& Materials, 686, 10-16. https://doi.org/10.4028/www.scientific.net/AMM.686.10

[22] Elbah, M., Yallese, M.A., Aouici, H., Mabrouki, T., \& Rigal, J. F. (2013). Comparative assessment of wiper and conventional ceramic tools on surface roughness in hard turning AISI 4140 steel. Measurement, 46(9), 3041-3056. https://doi.org/10.1016/j.measurement.2013.06.018

[23] Samardžiová, M. \& Neslušan, M. (2013). Development of Surface Roughness in Hard Turning of 100Cr6 Using Mixed Ceramic Cutting Tool with Wiper Geometry and Conventional Geometry. Research Papers Faculty of Materials Science and Technology Slovak University of Technology, 21(Special Issue), 193-198.

[24] Makadia, A. J. \& Nanavati, J. I. (2013). Optimisation of machining parameters for turning operations based on response surface methodology. Measurement, 46(4), 15211529. https://doi.org/10.1016/j.measurement.2012.11.026

[25] Jang, D. Y. \& Hsiao, Y. T. (2000). Use of ceramic tools in hard turning of hardened AISI M2 steel. Tribology transactions, 43(4), 641-646. 
https://doi.org/10.1080/10402000008982389

[26] Machado, A. R., Coelho, R. T., Abrão, A. M., \& Silva, M. B. (2012).Teoria da Usinagem dos Materiais (2nd ed.). São Paulo, SP: Blucher.

[27] Diniz, A. E., Marcondes, F. C., \& Coppini, N. L. (2014) Tecnologia da Usinagem dos Materiais ( $9^{\text {th }}$ ed.). São Paulo, SP: Artliber.

[28] Aslantas, K., Ucun, I., \& Çicek, A. (2012). Tool life and wear mechanism of coated and uncoated $\mathrm{Al}_{2} \mathrm{O}_{3} / \mathrm{TiCN}$ mixed ceramic tools in turning hardened alloy steel. Wear, 274-275, 442-451. https://doi.org/10.1016/j.wear.2011.11.010

[29] Shalaby, M. A., El Hakim, M. A., Abdelhameed, M. M., Krzanowski, J. E., Veldhuis, S. C., \& Dosbaeva, G. K. (2014). Wear mechanisms of several cutting tool materials in hard turning of high carbon-chromium tool steel. Tribology International, 70, 148-154. https://doi.org/10.1016/j.triboint.2013.10.011

[30] Zhuang, K., Xiaoming, Z., Dahu, Z., \& Han, D. (2015). Employing preheating-and cooling-assisted technologies in machining of Inconel 718 with ceramic cutting tools: towards reducing tool wear and improving surface integrity. The International Journal of Advanced Manufacturing Technology, 80(9-12), 1815-1822. https://doi.org/10.1007/s00170-015-7153-8

[31] Kurt, A., Yalçin, B., \& Yilmaz, N. (2015). The cutting tool stresses in finish turning of hardened steel with mixed ceramic tool. The International Journal of Advanced Manufacturing Technology, 80(1), 315-325. https://doi.org/10.1007/s00170-015-6927-3

[32] Abbas, A. T. M. (2016). Comparative Assessment of Wiper and Conventional Carbide Inserts on Surface Roughness in the Turning of High Strength Steel. Journal of Materials Science Research, 5(1), 32-45.

https://doi.org/10.5539/jmsr.v5n1p32

\title{
Contact information:
}

Jéferson Hilário NICOLODI, MSc, Assistant Professor

University of Passo Fundo (UPF),

School of Engineering and Architecture,

BR 285, 99052-900, Passo Fundo, Brazil

e-mail: jeferson.nicolodi@upf.br

\author{
Luiz Airton CONSALTER, PhD, Full Professor \\ University of Passo Fundo (UPF), \\ School of Engineering and Architecture, \\ BR 285, 99052-900, Passo Fundo, Brazil \\ e-mail: lac@upf.br
}

Orlando Mauricio DURÁN ACEVEDO, PhD, Associate Professor

Pontificia Universidad Católica de Valparaíso

Avenida Los Carrera 01567, Quilpué, Chile

e-mail: orlando.duran@ucv.cl

André João de SOUZA, PhD, Associate Professor

Federal University of Rio Grande do Sul (UFRGS)

Department of Mechanical Engineering (DEMEC)

Rua sarmento Leite 425, 90050-170, Porto Alegre, Brazil

e-mail: ajsouza@ufrgs.br 